\title{
Identifying Secondary Disasters Caused by Local Heavy Rain Using Remote Sensing Data
}

\author{
Etsuji ISHIGURO*, Hiroki HIYAMA*, Yuki TOGO*, Daitaro ISHIKAWA*, \\ Hiroaki NANBA**, and Hidefusa MIYAMA*** \\ *Faculty of Agriculture, Kagoshima University, 1-21-24 Korimoto, Kagoshima, 890-0065, Japan \\ **PASCO Inc, 6-6 Kamoike-Shinmachi, Kagoshima, 890-0064, Japan \\ ***PASCO Inc, 1-1-2 Higashiyama, Meguro-ku, Tokyo, 153-0042, Japan
}

\begin{abstract}
This study focused on identifying secondary disasters caused by the local heavy rains using remote sensing data. It was assumed that the trees, grown on the areas affected by a landslide were subjected to water-stress, since the roots of these trees had been damaged. The spectral response of a Japanese cedar canopy measured by a handheld spectroradiometer varied with water-stress levels. From this fundamental experiment, we developed indices, Normalized Differential Vegetation Index: NDVI and the ratio of green and red regions RVI, which could represent the level of water-stress. These results were confirmed using aerial photographs taken before and after the disaster and video camera images taken after the disaster. For the aerial photographs, the concept of activity, which represents the changes of water-stress, was introduced. The activity index, Act, was calculated with the following equation, $A c t=\left[R V I_{B}-R_{A} I_{A}\right] / R V I_{B}$, where $R V I_{B}$ and $R I_{A}$ represent the $R V I$ indices of before and after the disasters, respectively. These activity values represent the degrees of danger in a location.

Images of a video camera with band pass filters were analyzed. Among the several band pass filters, it was demonstrated that three band pass filters, $550 \mathrm{~nm}, 660 \mathrm{~nm}$ and $770 \mathrm{~nm}$, could be used. Indices were, then, calculated using the following equations, $N D V I_{B P}=\left(R_{770}-R_{660}\right) /\left(R_{770}+R_{660}\right), R I_{B P}=R_{550} / R_{660}$, respectively.

This study shows the identifying possibility of locating the secondary disaster prone areas using aerial photographs taken before and after disasters. Some issues on photo taking conditions are also discussed. Moreover, the effectiveness of using video camera images is demonstrated for situation in which the satellite data or aerial photographs are not available.
\end{abstract}

Key words: Activity index, Aerial photograph, Disaster, NDVI, RVI, Satellite data, Video camera image, Water-stress,

\section{Introduction}

About $70 \%$ of Japanese land area is mountainous. Consequently, many regions in Japan are liable to natural disasters. Especially, the southern part of Japan has been often struck by typhoons with heavy rainfalls. It has been, therefore, strongly desired to identify the hazardous areas affected by heavy rains earthquakes. It has been urgently desired, therefore, to identify the hazard areas affected by the heavy rains or earthquakes. However, it has not been possible, up to date, to identify these hazardous areas.

On the west side of Kyushu Island, cumulonimbus clouds had developed and flowed into the southern part of Kyushu Island from 0:00 a.m. to 8:00 a.m. on 20 th July 2003. At the Hishikari town office the recorded precipitation was $555 \mathrm{~mm} /$ day and it was a typical case of concentrated local heavy rain (Fuji 2003). By this local heavy rain, several landslides occurred in Hishikari and Minamata. Two persons died in the Oyamaguchi district of Hishikari and 19 persons died in the Hogawachi district of Minamata. Unfortunately, these areas could not be identified as hazardous at that time. This study focused on locating the places where secondary disasters would occur by local heavy rain using remote sensing data as the first step.

\section{Materials and Methods}

\subsection{Materials}

The aerial photographs of Minamata taken before the disaster at 11:10 on 23rd November 2000, and after the disaster at $15: 40$ on 21 st July 2003 were used to analyze the data. And the aerial photograph of Hishikari taken after the disaster at 15:00 on 21st July 2003 was also used. Moreover, on the ground truth many spectral images taken with a video camera were 
used for the analysis. Figure 1 shows the aerial photograph of Hishikari taken on 21 st July 2003, one day after the disaster and illustrates the places measured and taken spectral images with handheld spectroradiometer and video recorder, respectively.

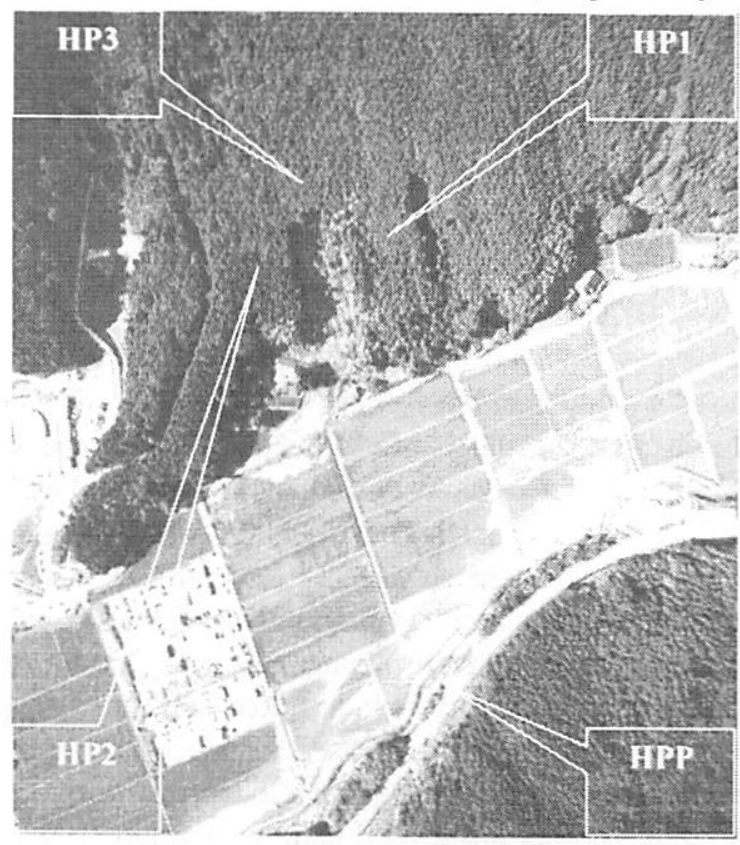

Fig.1. Aerial photograph of Hishikari taken on 21 st July 2003.

\subsection{Fundamental Experiment}

It was assumed that the areas once experienced landslides tended to suffer from secondary landslides because of the changes of ground conditions there. Also, trees grown there were subjected to water-stress since the roots of these trees had been damaged by the landslides. Japanese cedar (Cryptomeria japonica) was used as a model, as investigating the relationship between spectral characteristics and the effect of damaged roots. As it was very difficult to evaluate the degree of damaged roots, cedar, was cut at the trunk, and was kept in the laboratory. The spectral characteristics of a Japanese cedar canopy were measured by a handheld spectroradiometer (ELM Inc.) ranging from 400 to $1,100 \mathrm{~nm}, 3 \mathrm{~nm}$ intervals and 3 degrees of view angle. The time elapsed from the cut is considered to correspond to the level of water-stress. The spectral characteristics were calculated using the ratio of the reflected energies of a white board and the cedar canopy. In this case, spatial distances of the spectroradiometer from the cedar canopy and from the white board were kept constant and the intensities of illumination were revised by the integration time of the handheld spectroradiometer and with the irradiated lamp.

\subsection{Ground Truth}

We made ground truth twice. First, we surveyed the disaster area of Minamata on 18th Aug. 2003, about one month after the disaster. And, the second time, we surveyed the disaster areas of Minamata and Hishikari on 22nd Aug. 2003. In Minamata, landslides occurred along a mountain stream, affected area was $1.5 \mathrm{~km}$ long. In Hishikari, landslides occurred along the surface of a mountain in length of $300 \mathrm{~m}$.

The spectral characteristics of tree canopies grown in the neighborhood of the landslide and those grown far from the landslide affected areas were measured using the handheld spectroradiometer. Several spectral images were also taken by a video camera mounted with band pass filters. These images were taken using a white board as the reference because the values of spectral reflectance were calculated by these images. These band pass filters were corresponded with Landsat-5/TM bands, 440nm, 550nm, 660nm and $770 \mathrm{~nm}$. The widths of these band pass filters were \pm $8 \mathrm{~nm}$, respectively.

\subsection{Image Analysis}

Video images were captured by the video camera. The aerial photographs were corrected to the topographic map by setting several ground control points (GCP) using ERDAS IMAGINE software. These two images were then processed to be NDVI and RVI images so that they could be used with other image processing.

\section{Results and Discussions}

\subsection{Spectral Characteristics of the Cedar Canopy in the Fundamental Experiment}

Changes of spectral reflectance of the cedar canopy with time are shown in Fig.2. In this experiment, as leaves were not densely grown, we could avoid the backscattering effect with a black board. These reflectance measurements were smaller than those from the usual tree canopy. However, it was considered that the percentage of leaves in observed area was constant. These curves demonstrated the usefulness of analyzing the water-stress. With the increase of the elapsed time, reflectances decrease. If we can assume the elapsed time corresponds to the degrees of water-stress, these results show the possibility of identifying the degree of water-stress of trees by using spectral characteristics.

The mean spectral reflectances of the cedar canopy corresponding to each band of Landsat-5/TM were calculated. With the increase of the elapsed time, each mean spectral reflectance decreased linearly. As these results show the possibility of usefulness of 
Landsat-5/TM data, many indices were considered.

It was concluded that NDVI was the best index among indices for evaluating the degree of water-stress of a tree, as shown in Fig.3. It was also clarified that RVI ( $=$ Green/Red) is a good index if near infrared data, cf. Landsat-5/TM, are not easily available.

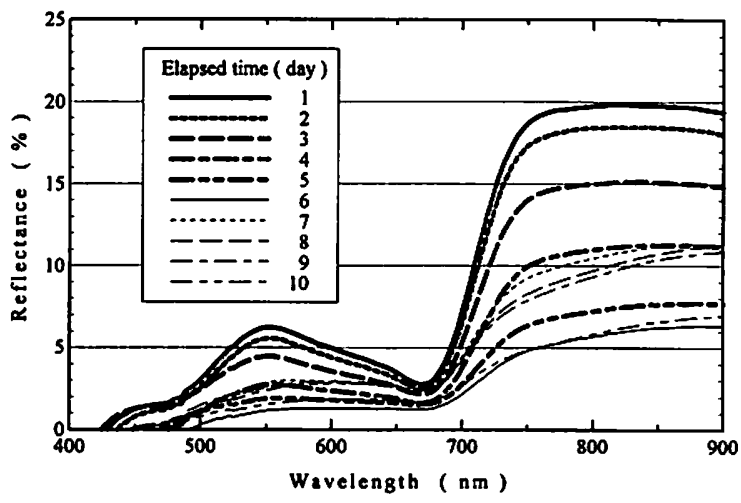

Fig.2. Changes of spectral reflectance of cedar canopy according with elapsed time.

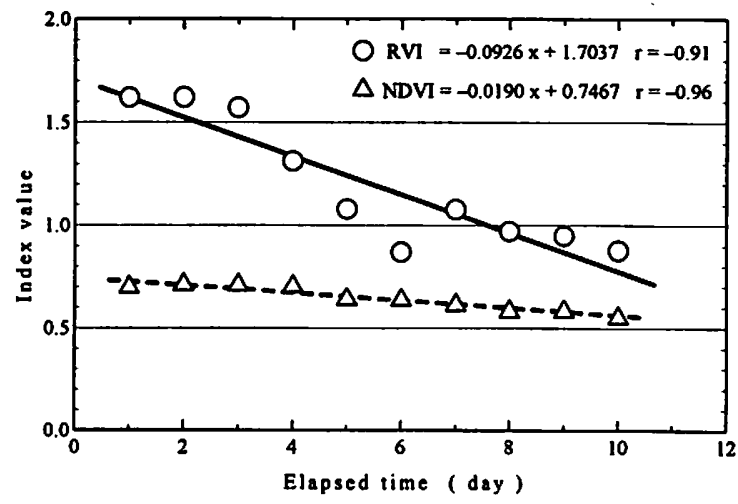

Fig.3. Relationships between NDVI and RVI value and water-stress (elapsed time).

\subsection{Spectral Characteristics of the Cedar Canopies in the Ground Truth}

Spectral characteristics of the cedar canopy in the Hishikari area is shown in Fig.4. This ground truth was carried out on 22nd August 2003, about one month after the local heavy rainfalls. In this figure, HP1 and HP2 show the observations of sites near where landslides occurred and HP3 shows sites apart from there.

In the visible region, reflectances of the tree canopies were not changed for these three points. However, reflectance in the near infrared region varied greatly. HP3 showed the highest values. HPI presented the lowest values. As a result, it was considered that trees grown in HP1 and HP2 were affected by landslides though those in HP3 were not. These results coincided with the fundamental results and other experiments (Ishiguro et al. 1998; 1999).

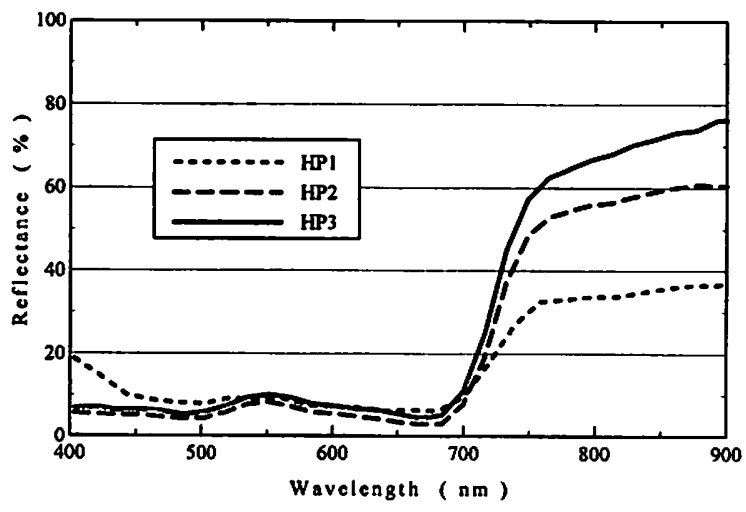

Fig.4. Spectral characteristics of standing cedar measured at Hishikari on 22nd August 2003.

\subsection{Analyzing of Aerial Photograph}

The RVI images were constructed using the aerial photographs taken before and after the disaster. Activity [Act] was defined with the change of the water-stress before and after the disaster and expressed as the following equation:

$$
\text { Act }=100\left(\mathrm{RVI}_{\mathrm{B}}-\mathrm{RVI}_{\mathrm{A}}\right) / \mathrm{RVI}_{\mathrm{B}}
$$

where $R V I_{B}$ and $R I_{A}$ show the RVI value for before and after of the disaster, respectively. The Act image is shown in Fig.5. In this figure, the white parts show the high Act values from the definition. These white parts indicate the drastic change of water-stress before and after the disaster and the dark parts indicate the no-change of water-stress. However, these aerial photographs were not taken at the same time, i.e., one was taken at 11:10 and other was at 15:40. The interpretation of the shaded area is complex; the left side in the upper part of these photographs includes both sunny and shaded places. Then those areas shown to be white parts involved the differences of the sunny and shady places. Except for these areas, it was shown that the white parts will be very dangerous than the other areas. Unfortunately, these results were not verified, it was confirmed, however, that secondary disasters had occurred on the regions affected with water-stress by the huge earthquake (Ishiguro et al., 1998; 1999).

\subsection{Portable Video Image Analysis}

Figure 6 shows a $\mathrm{NDVI}_{\mathrm{BP}}$ image. In this figure, the band pass filtered images of $660 \mathrm{~nm}$ and $770 \mathrm{~nm}$ were used. These positions were corrected with GCP and corrected RMS errors were smaller than 0.05 pixels. These were constructed from $R \mathrm{RVI}_{B P}=R_{550} / \mathrm{R}_{660}$, and 
$\mathrm{NDVI}_{B P}=\left(\mathrm{R}_{770}-\mathrm{R}_{660}\right) /\left(\mathrm{R}_{770}+\mathrm{R}_{660}\right)$, respectively.

However, as the objects, i.e., tree crowns, were very small, these images were affected with the clearance distance of those trees.

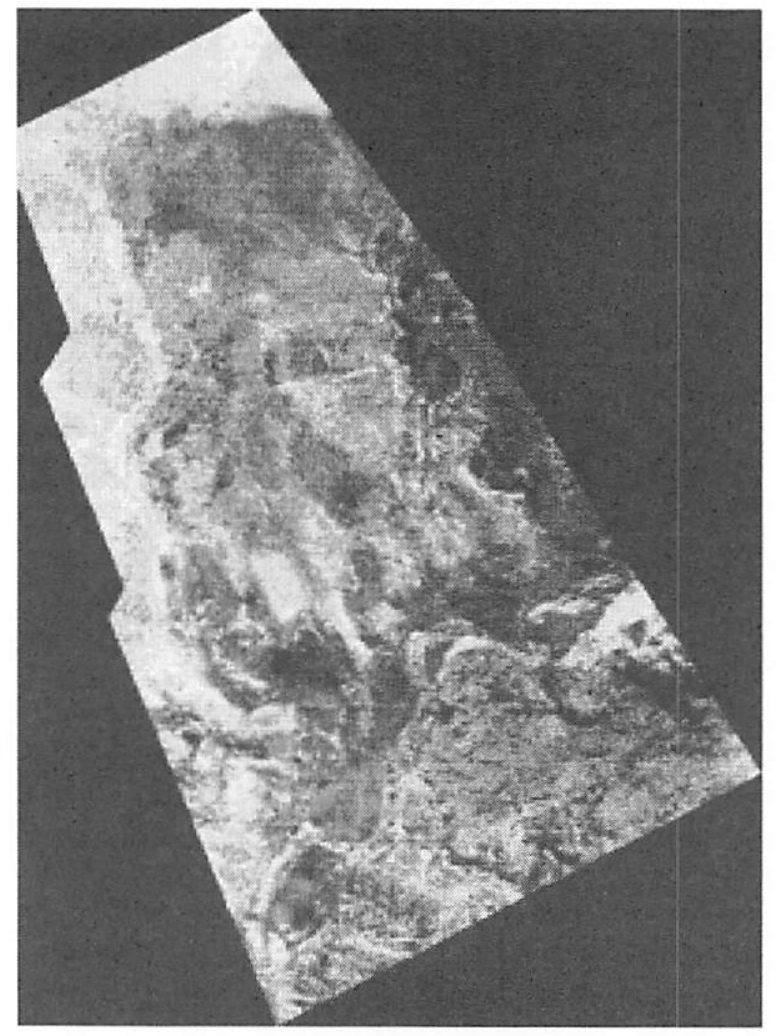

Fig.5. Activity image

Comparing the images of $\mathrm{RVI}_{\mathrm{BP}}$ and $\mathrm{NDVI}_{\mathrm{BP}}$, it was certain that the brightness values of the $\mathrm{NDVI}_{\mathrm{BP}}$ images are slightly higher than those of $\mathrm{RVI}_{\mathrm{BP}}$ images. These results coincided with the fundamental results. Moreover, it is clearly recognized that the spatial resolution of the aerial photographs are clearer than those of satellite images.

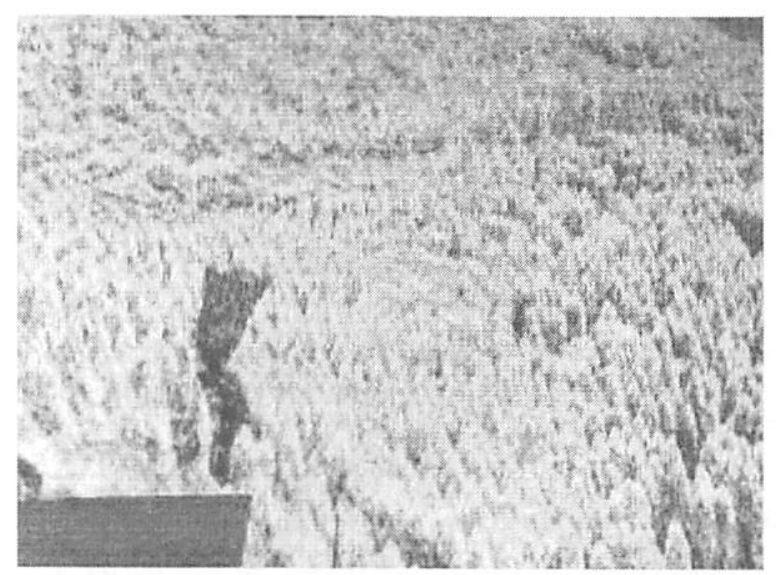

Fig.6. $\mathrm{NDVI}_{\mathrm{BP}}$ image composed from the spectral video camera images.
Therefore, for locating the hazardous areas, video images would be more effective than satellite images.

From the above results, we can propose that if we will not be able to obtain aerial photographs or satellite images immediately after a disaster, a spectral video image will be a practical and effective alternative.

\section{Conclusions}

The methods for locating the secondary disaster prone areas caused by local heavy rains using remote sensing data were studied with fundamental experiments and ground truth. Following results were obtained.

1. In the ground truth, spectral reflectance of near infrared of the canopy of trees grown near the places landslides had occurred was smaller than that of grown far from there. These results agree to the fundamental results.

2. Water-stress indices derived from the results of the characteristics of the reflectance of the cedar canopy show their potential ability to locate the secondary disaster prone regions.

3. The data such as aerial photographs or satellite images will not be necessarily obtained timely. In that case, spectral video images taken in the near infrared region can be an effective alternative to them.

By refining these algorithms, we will be able to develop a reliable tool to identify secondary disaster prone areas. We also hope to establish methods to accurately identify natural disaster regions.

\section{References}

Fuji, T., 2003: Local heavy rain report at the Hishikari town on the 20th July 2003, (Kagoshima Local Meteorological Station): private communication.

Ishiguro, E., and Tabata, T., 1998: Study on the possibility of identifying the hazard areas by the earthquakes using satellite data. The Kyushu Chapter of the Society of Agricultural Meteorology of Japan, II(7), 45-48.

Ishiguro, E., Tabata, T., Jitouzono, T., Teramoto, Y., Shoji, J., and Kanemasu, E.T., 1999: Development of Hazard Map by Earthquake using Satellite Data. Proceedings on 1999 ASAE Annual International Meeting. No.99-3122. 